\title{
Mapping and characterizing animals' places of interest in forest environment
}

\author{
Laurence Jolivet $^{\mathrm{a}, *}$, Florian Masson ${ }^{\mathrm{b}}$, Sonia Saïd ${ }^{\mathrm{c}}$ \\ ${ }^{a}$ LASTIG, Univ Gustave Eiffel, ENSG, IGN, F-94160 Saint-Mandé, France, 1st Author-laurence.jolivet@ign.fr \\ ${ }^{b}$ Bureau de Recherches Géologiques et Minières, 2nd Author-f.masson@brgm.fr \\ ${ }^{c}$ Office français de la biodiversité,3rd Author - sonia.said@ofb.gouv.fr \\ * Corresponding author
}

\begin{abstract}
Fauna impacts its environment as well as spatial environment influences fauna space use. Forest management implies taking into account pressure from animals in fragile-balanced patches. Our goal is to propose maps that would benefit forest planning by reflecting individual movement and space use depending on the animal species and local spatiotemporal environment. The study case focuses on two species, roe deer and red deer, and on a forested site in the northeast of France. Movements of several individuals were analysed from collected GPS locations. Foraging places likely to correspond to intense research behaviour were computed using the First-Passage Time method. These places were assumed as being of interest and were characterized with landscape features and temporal information. Maps were produced to synthetize information about foraging places by defining adapted symbolizations. Then maps about functional space were proposed based on extrapolation of favourable or avoided areas from the characterized observed foraging places and space use. Landscape patches were mapped according to a gradient of potential interest by animals' species, in order to highlight needs of specific planning actions in the forestry context. Map displays were driven by forestry end-use and designed so that to be compliant to a numeric geographical portal, giving access to different available on-line layers and computed created ones.
\end{abstract}

Keywords: fauna, forestry, landscape, map, first-passage time

\section{Introduction}

Wildlife space use is closely related to the characteristics of spatial environment. By its composition and structure, spatial environment influences the presence and movements of animals at individual, population and species levels (Ethier et al., 2011; Nellemann et al., 2001). For forest dwelling ungulates such as deers, habitat quality including food availability has an effect on individual characteristics like body mass or home range size, and therefore on population dynamics and spatial distribution (Kjellander et al., 2006; Widmer et al., 2004). Interactions exist in both ways. Animals act on environmental components through behaviours like foraging, debarking or trampling (Plumptre, 1993).

The application context of the presented work is the consideration of fauna space use in forest management. Maintaining the good functioning of ecosystems in forested environment is a major challenge as interrelated matters are at stake: the good health of vegetation and tree stands, habitat conservation for wildlife, access maintenance for recreation and for economic activities. Focusing on wildlife, one issue lies in the fact that animals may be present in given areas which can hardly bear consequences of their presence. For instance, roe deer likes to browse saplings and young shoots. As a consequence, forest patches such as regeneration patches containing young trees may be intensively used while they support few disturbances to be able to grow (Hanley, 1996). Locating the specific patches which call for the presence of animals is one key step in the whole process of forest management.

Patches are preferably used depending on the needs of animal species. The environmental variables to be taken into account are landscape characteristics, temporality and presence of other individuals and species. Landscape characteristics include the spatial composition of elements such as vegetation and topography that can correspond to food resources and energy cost (Boulanger et al., 2015; Rooney, 2001). They also concern spatial configuration providing movement corridors or obstacles and determining visibility. Temporality is about the hour of the day, the season or other significant timespan for space use. Presence of other animals, including humans, has an influence as it may result in encounter or avoidance response.

Animals' space use is known based on observations and recorded locations. GPS device has enabled monitoring individuals' locations at high spatial precision and temporal frequency. Descriptions of spatial environment are available in existing geographical databases. From these databases, oriented readings of the space can be provided. The functional space consists in features that may influence animal space use (Forman et al., 1986). Features can be used because meeting requirements or they can be unused or avoided. Functional space can be defined with respect to an individual or a group of individual, of same or different animal species. Highlights on specific aspects can also be formalized, as 
for foodscape or fearscape (Olsoy et al. (2015). The challenge in geographical information science is to extract and display this functional space and so any information meaningful for explaining animals' space use (Andrienko et al, 2012; Spretke et al., 2011). Information extraction targets environmental variables. Display deals with synthetizing extracted information based on data analyses and with visualizing it thanks to adapted semiology. In the context of forest management, a significant highlight is about places of interest. A place of interest is defined in this article as a part of space corresponding to a specific behavior (forage, rest, move) and so a notable presence of an animal. A place can be effective because presence is observed. It can be potential because assumed as in favor for animal presence.

The objective is to identify places of interest from individuals' GPS location data and to characterize and map these places based on land description databases. The study focuses on the two species roe deer and red deer and on a site corresponding to a hilly and forested environment. The final maps are expected to be media for exploring animal's GPS datasets containing non-explicit knowledge, for disseminating and communicating on analysis results and integrating them in forestry and land planning actions.

\section{Material and method}

\subsection{Material}

\subsubsection{Study case}

The study case is about the species roe deer and red deer living in a forest environment. The monitoring site is the reserve of La Petite Pierre located in the Northern Vosges in the East of France. The reserve is managed by Office français de la biodiversité (OFB, the French biodiversity agency) and Office national des forêts (ONF, the French forestry agency). It covers about $30 \mathrm{~km}^{2}$. Landscape is enclosed and cover is mainly forested. Stands are about half deciduous trees, beech mostly, oaks and hornbeam, and half coniferous, including firs, spruce and scots pine (Storms et al., 2004). Terrain is hilly and altitude ranges from 180 meters to 420 meters. Trails and forest roads are open for hiking, though trespassing aside is not allowed. Some clusters of buildings are scattered. Disturbances for wildlife may come from leisure activities (hikers), service activities and vehicle traffic (foresters), and from regulated hunting occurring a few days a year. Close surroundings within one kilometre from the reserve boundaries are also forested. Beyond that distance, landscape opens on crops, grasslands and small inhabited places.

Roe deer and red deer have distinct spatial behaviour due to their specific needs and rhythm. Our research was carried out on adult females as their home range is set and few migration movements are observed. Female roe deer is solitary or lives in small family groups. Female red deer lives in herds. Roe deer has limited home range (Mysterud, 1999). However, home range core can shift depending on the season (Le Corre et al., 2008). In the study site, average home range area is around $0.5 \mathrm{~km}^{2}$. Diet is mostly composed of semi-ligneous vegetation found in shrub. They are income-breeder (Saïd et al., 2005) so individuals forage and rest alternatively. Red deer has larger home range, even if the core may cover only a small part of it (Náhlik et al. 2009). In the study site, home range area is in average $2.5 \mathrm{~km}^{2}$, though it can vary over time. Individuals are more likely to remain less active and to favour tree cover during the day. They forage more actively at dawn and dusk (Ager et al., 2003), possibly in open fields. Their diet is composed of semi-ligneous as well as ligneous and grass vegetation (Boulanger et al., 2015).

\subsubsection{Animal's GPS locations and environmental databases}

Animals' GPS locations were collected by OFB (Storms et al., 2008). A dataset was extracted so that to target shared behaviours empirically observed in the study site. It concerns 3 roe deers and 6 red deers. For each individual, recordings cover 5 days in average in 2007 and 2008. They were scheduled every 5 minutes and the success rate is around $85 \%$. Spatial accuracy of the locations is estimated between 0 to 30 meters.

Description of the environment comes from the databases specified and produced by Institut national de l'information géographique et forestière (IGN, the French mapping agency). The different databases correspond to a thematic point of view and to a spatial and temporal resolution. They provide information about topography, land cover (forest stands, hydrography, buildings, roads, grasslands, crops) and land use (forestry, industry, services, dwelling, agriculture). Geometrical accuracy is under metric for punctual elements such as water bodies, buildings, roads. Resolution goes down to $25 \mathrm{~m}^{2}$ for altitude, to $500 \mathrm{~m}^{2}$ for wooded areas and to $5000 \mathrm{~m}^{2}$ for forest stands. Databases can be visualised in the French national geographical portal (https://www.geoportail.gouv.fr/) and can be downloaded from the dedicated geographical services website (https://geoservices.ign.fr/).

\subsection{Method}

The methodological approach is to analyse and map animals' space use based on the GPS locations and with regards to the environmental data. First, movement patterns are computed from GPS locations according to distance and time information. Second, places of interest are located from the movement patterns and characterized with landscape features. Third, the functional space at both individual and study site scales is determined from the characteristics of the places of interest. Then, visualizations of the analysis results are provided requiring choices about displayed geometries and symbolization.

\subsubsection{Computing foraging stops in movement patterns}

A movement pattern is a description of movement. Patterns are useful to highlight common or uncommon individual behaviours with respect to its species, here roe 
deer and red deer, and to carry out global comparison between species. Our target is to discriminate between different types of places of interest according to specific behaviour. Stops and moves are thus interesting movement patterns (Buard, 2011; Spaccapietra 2008). A stop is defined as a set of successive known locations corresponding to low speeds, relatively to the whole dataset, within a limited area. In our case, this definition of stop was extended and divided into two types: a foraging stop with an active behavior, and a resting stop with no or little movement. A move corresponds to successive locations with relatively long travelled distances and high speeds. Individual movement patterns were then planned to be filled in with the foraging and resting stops, and moves. The priority is to identify sensitive forested patches potentially under pressure of ungulates, so the focus in this article is remaining about foraging stops.

In our study case, animal movements are known from GPS locations containing spatial coordinates and a time stamp. Patterns were set using geometrical description indices: estimated distances and speeds. Distances were calculated based on a linear interpolation between consecutive locations, which corresponds to the shortest path. Even if fixed time interval was scheduled, there are $15 \%$ missing locations, and so speeds were estimated from distances and achieved time length. Estimated distances are likely to be shorter than effective distances and estimated speeds are likely to be higher. Description indices can then be synthetized and weighted using measures such as average, maximum, variance or standard deviation. These measures are to be broken down by consistent time units like a day, a season, a year or a life time, and by individual or group of individuals.

To detect foraging stops into animal movement, the selected algorithm is the First-Passage Time analysis (FPT) (Fauchald et al., 2003; Le Corre et al., 2008). This algorithm is adapted to identify intense research behaviours. It extracts groups of points, and so associated periods of time and areas when and where the pace of movement is often changing. These changes are assumed to indicate an intense searching activity like foraging. The FPT algorithm is based on the time length an individual would spend to cover a distance corresponding to the radius of a circle and so allow quantifying the spatial scale of time period corresponding to intensive research effort. In our implementation of the method, individuals were considered and the chosen time unit was one day i.e. 24 hours (several days per individual). The first step of the FPT method is the calculation of the variance of the logarithm of reaching times, as a function of radius value. Reaching time, or first passage time, is computed for each GPS location and corresponds to the time length the animal remains within a circle of a certain radius. Radius values corresponding to local maxima, i.e. high variance, are extracted. They are considered as relevant spatial scales of research effort. In our case, radius values less than 30 meters are not taken into account due to GPS accuracy. The lowest radius value for local maximum over 30 meters is selected. The other radius values matching local maxima are also stocked in order to be associated to larger scale of search behaviour, though they correspond to less intensively located research effort and will not be integrated in this article. The second step of the FPT method is to plot the reaching time values according to the chronological GPS points and to select groups of successive points depending on two parameters (Figure 1). One parameter is the minimum threshold in order to select high reaching time values. This threshold may slightly vary depending on the individual and on the recording day. Value was set between 1 and 2 hours. The second parameter is the minimum number of successive points, also meeting the first parameter value. It was set to 12 points, with a leniency of 3 maximum successive points that can have lower reaching time values than the first parameter threshold value. The value of 12 is consistent with the minimum number of points to estimate areas corresponding to home range from GPS points. The result is clusters including at least 12 GPS points corresponding to high variance radii. Clusters of points correspond to area-restricted search (ARS) behaviour at a certain range (relevant selected radius value) which can vary between clusters of the same point dataset. The FPT method was implemented in a R script.

\subsubsection{From movement patterns to places of interest}

Foraging places of interest were deduced from foraging stops which are part of movement patterns. Those places are assumed to contain interesting features for fauna to feed. They correspond to intense presence of an animal and active sampling behavior on vegetation. They may require from foresters protection measures for stands. Other types of places of interest are likely to be less intensively sampled: resting places and transitional places corresponding to notable moves. Foraging places were located based on the ARS point clusters derived from the FPT algorithm. For each cluster, a convex hull polygon was interpolated. The method generally over-estimates areas, though it guarantees covering the place. The resulted geometry is called the ARS polygon. The descriptions of the ARS polygons are inputs for the descriptions of foraging places of interest.

The geometries of ARS polygons were completed with information about three themes: the animal's behaviour corresponding to the ARS, landscape features and environmental context. The $1^{\text {srt }}$ theme about the animal's behaviour was obtained from the GPS data. It contains: the FPT radius value; the area value of the ARS polygon; the covered distance by the animal; the average movement speed; when available the activity derived from head movements data given with the GPS data; the time length of exploitation of the ARS polygon. The $2^{\text {nd }}$ theme is about landscape features. Features were selected depending on their relative cover in the ARS polygon. Some features were summarised by average values on the whole polygon. They are: presence of absence (clear cut) of forest cover; if presence, number of distinct forest stands covering the ARS polygon; the main, second and third forest stands; presence of other land covers than 
forest such as meadows, crops, roads and buildings; the topography with average values of altitude and slope, and the main orientation of the land. Even if traffic is little over the study site, road are considered as they may be associated with breaks in forest cover. Then $3^{\text {rd }}$ theme concerning the environmental context is about: the date and the corresponding season; the starting and leaving hour in and out the ARS polygon, and the corresponding period of the day (dawn, midday, dusk or night). The GIS layer containing the ARS polygons were intersected with the layers containing the animals' GPS points and the existing descriptions of the geographical space. Each piece of information was edited as a field in the attribute table of ARS polygons layer in order to facilitate further mapping. Basic fields were added: individual identifier, species name, a free-text field for any notes about the data. Spatial analysis and edition of tables were carried out using GeOxygene GIS open-source platform (Badard et al., 2004).

\subsubsection{From places of interest to functional space}

Besides locating effective places of interest, the other aim for forest application is to be able to characterize a whole study site. Potential places of interest are to be determined, out of the space where and when animals were tracked. These potential places constitute the functional space at a site extent. They can be qualified according to environmental features as in favour or against the presence of animals. The approach is to characterize the computed foraging places of interest and to extrapolate from this characterization to a characterization on the extent of the study site. Characterizing foraging places of interest consists in identifying spatial preferences or avoidance in regards with the available space (Matthiopoulos, 2003). A spatial preference corresponds to favourable landscape elements for animal presence. It is detected based on a significantly more intense use compared to use in the surrounding available space. On the contrary, spatial avoidance corresponds to landscape features of little benefit and so to significant scarce presence or absence.

Spatial preferences and avoidance were detected at two scales, foraging places of interest and used space. First, foraging places of interest were compared with the observed used space per individual. Descriptions of foraging places of interest based on the ARS polygons were synthetized. The observed used space correspond to all GPS records for an animal. It includes resting and transitional places. It is an input for determining home range. Individual homes ranges were computed using convex hull of GPS points and described with same landscape features than for ARS polygons (2.2.2). Second the used space was compared with the whole study site. The study site extent of the reserve was also described with landscape features. The corresponded functional space is made of patches containing landscape features significantly qualified in favour or not for roe deer and red deer. Statistical tests of were applied to estimate significant differences between the used space and the available space. The study site was divided into a regular grid with a resolution of $25 \mathrm{~m}$, matching the DTM resolution and consistent with the GPS accuracy. The pixels of this grid were described based on landscape features. Pixels were compared between presence and absence of animals using a Mann-Whitney statistical test. Then, pixels were compared according to the type of movements using a Chi-square test. A high number of GPS points in a pixel is assumed to be stops and slow movements and associated to places of interest for foraging and resting activities. A low number of GPS points is assumed to be fast moves and so associated to transitional places.

The GIS layer of the functional space was built as a collection of polygons computed from the existing objects in the environmental databases. As the study site is a forest environment, the main land cover is about the forest stands. Polygons were defined from forest stand data and then geometrically modelled, cut or merged according to the significant combinations of landscape elements. An attribute field to the polygons was defined related to a gradient of potential interest for roe deer and red deer. The three potential values are high, medium and low. Implementation of the statistical tests was done in $\mathrm{R}$ scripts, and of spatial analysis in GeOxygene GIS.

\subsubsection{Defining mapping specifications}

Mapping specifications were defined for displaying places of interest of roe deer and red deer. The mapping interface is a geographical portal with Web Map Service (WMS) and Web Feature Service (WFS) data flows as cartographical backgrounds: base maps, aerial and satellite images, thematic-oriented maps (e.g. a forestry map). The numeric interface allows overlapping of available on-line institutional layers and layers dedicated to a study case. The adding value is the display of the characterized places of interest, both effective and potential ones. Cartographic rules aim at reaching readability and clarity of the displayed information (limited number of elements, adapted level of detail). Displayed attributes on a same map are so planned to be in limited number. Besides, it is expected that the association of two or more attributes makes sense in a common reading. Graphic semiotics allows optimizing a shared understanding of displayed information, based on relevant visual variables (Bertin, 1967). Visual variables are to be appropriately allocated to attributes, in order to differentiate them, to remain evocative to the displayed information and to support efficient communication.

Challenges are to take into account differences of spatial and temporal scales for effective and potential places and to display the great number of attributes and attribute values concerning those places. Effective places of interest corresponding to the ARS polygons have limited extents and correspond to intense research behaviour for a short period of time. Functional space defined by potential places has a study site extent and is assumed to be relevant as long as there are few landscape changes. Input geometries for mapping effective foraging places of interest are the ARS polygons and the associated GPS locations. Besides individuals and species, cartographical 
display should offer a synoptic view of the three themes indicated about ARS polygons in 2.2.2, animal behaviour, landscape features and environmental context. Concerning the potential functional space, the input geometries are the computed polygons of the patches in favour or not for animal presence. The defined semiology has to be adapted for the qualitative gradient of potential interest. All produced maps were done in QGIS.

\section{Results}

\subsection{Description of recorded movements and detected foraging stops}

Based on the GPS dataset of the study case, average daily distance covered by one individual is $8 \mathrm{~km}$ for roe deer and $10 \mathrm{~km}$ for red deer; average daily speeds are respectively for the two species 350 meters per hour and 450 meters per hour; covered areas are in average around respectively $0.1 \mathrm{~km}^{2}$ and $0.6 \mathrm{~km}^{2}$. Consistently with the behaviour of income breeder, roe deers have regular periodic high-speed movements, observed every 4 or 5 hours. Red deer have high-speed movements observed approximately twice a day and smaller or no movements in between. Detected foraging stops assimilated to intense research effort behaviour are described as follow. They correspond to the ARS clusters of GPS points, computed with the FPT method.

- For roe deer, 1 to 4 foraging stops per individual and per day, with an average of 2. For 5 days of study, 9 stops in average were computed per individual. Percentage of GPS points corresponding to a foraging stop is in average equal to $20 \%$ per individual and per day. The time length of a stop ranges from 1 to 5 hours with an average of 2 hours;

- For red deer, 1 to 6 foraging stops per individual and per day. In average, the numbers of stops were a little higher than 2 and so than for roe deer. For 5 days of study, 11 stops in average were computed per individual. Percentage of points corresponding to a foraging stop is in average equal to $30 \%$ per individual and per day. The time length of a stop ranges from 1 to 10 hours with an average of 3 hours.

There are slight differences between the two studied species in number of foraging stops. Stronger variations in time length can be partly explained by the fact that roe deer alternates relative short periods for foraging and for resting while red deer is globally biphasic during one day and so has longer continuous active phases.

\subsection{Characterization of the foraging places of interest and animal space use}

The ARS polygons were interpolated by convex hull from the ARS clusters. In the study case for roe deer, their areas vary from $200 \mathrm{~m}^{2}$ to $2500 \mathrm{~m}^{2}$ (average value: $600 \mathrm{~m}^{2}$ ) (Figure 1). For red deer, their areas vary from $150 \mathrm{~m}^{2}$ to $11.000 \mathrm{~m}^{2}$ (average value: $1300 \mathrm{~m}^{2}$ ).
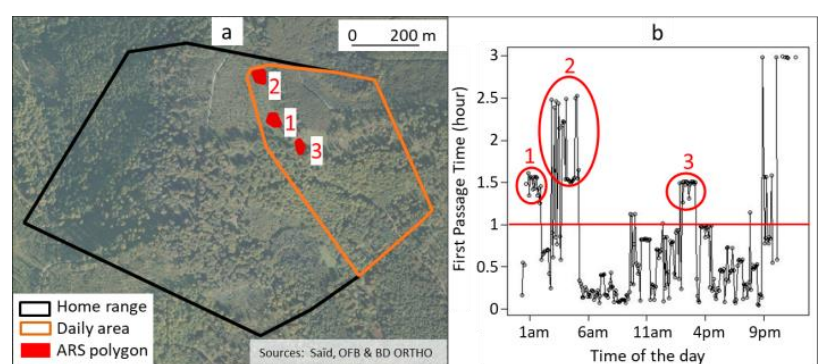

Figure 1. A roe deer's space use: (a) estimated home range, the estimated space use during one day in September, 3 ARS polygons computed during the same day; (b) plot from the FPT method to select the 3 corresponding ARS GPS point clusters.

Synthetized description of ARS polygons revealed that the main forest stands covered by roe deer during intense research effort are young plantations and cuttings $(50 \%$ of the polygons), and mixed hardwood and softwood plantations (40\%); the ones covered by red deer are mainly young plantations and cuttings (50\% of the polygons), then oak (20\%). For red deer specifically, $10 \%$ of the ARS polygons are located in clearings and meadows, outside at the edge of the forest cover. Slopes are moderate, in average 10 degrees for roe and red deer.

ARS polygons were located with respect to the observed used space. Individual space use was estimated daily by convex hull from GPS points. In average, it covers an area of $0.1 \mathrm{~km}^{2}$ for roe deer (an example in Figure 1) and $0.5 \mathrm{~km}^{2}$ for red deer. ARS polygons are then at least 40 times smaller than estimated daily space use. The dataset of GPS locations is large enough (1000 points at least per individual) and is well distributed over time (recording days over all seasons), so that to estimate annual space use, or home range. In average per individual, it covers an area of $0.5 \mathrm{~km}^{2}$ for roe deer (Figure 1) and $2.5 \mathrm{~km}^{2}$ for red deer.

The individual locations from the GPS dataset were described according to the same three themes than for ARS polygons. GPS points are mostly located in young plantations and cuttings, 20\% for roe deer and 30\% for red deer. The following most visited stands for both species are hardwood (oak, beech) and mixed plantations. Red deer space use includes patches with other various land covers, especially containing ligneous plants and grass. The description of foraging places of interest related to the most visited forest stands and land covers is roughly similar with space use in home ranges.

\subsection{Estimation of the functional space within the study site}

Description of space use from GPS locations were compared to the whole study site corresponding to the available space. Spatial preference and avoidance were assumed and then tested. While computing the MannWhitney test about the type of forest stands, presence is significantly higher, based on the p-values, in young plantations and cuttings and in oak stands for roe deer and red deer. There is a general significant absence in beech stands and in stands with a mix of softwood trees. For roe deer, there is an added preference for mixed 
stands. For red deer, there is an added avoidance for mixed stands with a majority of hardwood trees. When applying the Chi-square test to discriminate movement according the speed, young plantations and cuttings and in oak stands are used for slow and fast moves for both species. Beech stands are used for fast moves by roe deer. Mixed stands are used for fast moves by roe deer and red deer. Other types of available forest stands do not output with significant p-values. While computing the MannWhitney test about slopes, the used space corresponds to significantly lower values ( 8 degrees for roe deer and 13 degrees for red deer in average) compared to available space (17 degrees in average). Concerning other landscape elements, avoidances were computed for roe deer concerning trails and buildings. Preferences were computed for red deer related to waterways and forest roads. It may be due to particular plant species and to an ease in movement. In the roe deer and red deer functional space, high potential interest is then for young plantations and cuttings and oaks and shallow slope. Medium potential interest is for roe deer associated to mixed stands and for red deer to space near waterways and forest road. Low potential interest is for both species corresponding to softwood trees and no buildings.

\subsection{Map designs about effective places of interest and of functional space}

\subsubsection{Display of foraging places of interest}

A first design proposal for displaying foraging places of interest is to exploit visual variables at best applied on the input ARS polygon. Use of written text in labels is a possibility in addition to visual variables. Each attribute field of the ARS polygons is to be displayed with an adapted visual variable depending on its type (number, percentage, qualitative information). It can potentially be displayed by several visual variables (e.g. qualitative information by colour or shape). The visual variable values are defined depending on the range of the attribute values. Combinations of visual variables were determined in order to display two to a maximum four attributes on the same ARS polygon geometries. Table 1 presents a selection of attributes to map and the possible visual variables, from which combination should be defined in order not to apply the same visual variable twice.

\begin{tabular}{|l|l|l|l|l|l|l|l|l|l|}
\cline { 2 - 8 } \multicolumn{1}{c|}{ Visibility of background layers } & \multicolumn{1}{l|}{ No visibility } \\
\hline $\begin{array}{c}\text { Visual } \\
\text { variables }\end{array}$ & $\begin{array}{c}\text { Dot or } \\
\text { line } \\
\text { pattern }\end{array}$ & $\begin{array}{c}\text { Border } \\
\text { thickness }\end{array}$ & $\begin{array}{c}\text { Border } \\
\text { style }\end{array}$ & $\begin{array}{c}\text { Border } \\
\text { hue }\end{array}$ & $\begin{array}{c}\text { Border } \\
\text { colour } \\
\text { shading }\end{array}$ & $\begin{array}{c}\text { If } \\
\text { circle: } \\
\text { size }\end{array}$ & Text & $\begin{array}{c}\text { Color: } \\
\text { hue }\end{array}$ & $\begin{array}{c}\text { Color: } \\
\text { shading }\end{array}$ \\
\hline Season & & & & & & & & & \\
\hline $\begin{array}{l}\text { Time of } \\
\text { arrival }\end{array}$ & & & & & & & & & \\
\hline $\begin{array}{l}\text { Time } \\
\text { length }\end{array}$ & & & & & & & & & \\
\hline $\begin{array}{l}\text { Main } \\
\text { forest } \\
\text { stand }\end{array}$ & & & & & & & & & \\
\hline
\end{tabular}

Table 1. Possible visual variables (cells filled in grey) to display four attributes about places of interest, that can be carried by polygons or circles, and associated with the possibility of seeing the background layers.

A second map design proposal is to use circle geometry instead of the ARS polygon geometry, and centred on its centroid. Circles are less accurate than convex hulls in regards with the extent and shape of the computed ARS clusters of GPS points. Though a circle symbol is relevant to display the FPT radii selected to extract the ARS clusters. Concerning the WMS and WFS cartographical background layers, it is set as possible to activate or to hide them. If activated, information from background layers may be read within foraging places of interest, whether symbolized with convex hull polygons or circles. As this information may be redundant with some attribute values (e.g. main forest stand), the number of necessary visual variable decreases. Though to maintain visibility of background layers, some visual variables such as hue, shading and texture cannot be applied on the geometry for foraging places. Figure 2 illustrates foraging places of interest of one red deer during three distinct days. The map meets the following specifications: use of the ARS polygon geometry, display of four attributes (season, period of the day, time length and main forest stand), visibility of background layers within places of interest.



Figure 2. Foraging places of interest of a red deer during three day: input ARS polygon geometries were used to carry visual variables for attributes characterizing places, and an aerial image was set as background layer.

The season attribute is displayed with border style (full or dotted) relying on the shape visual variable. The period of the day is in this case based on the time of arrival. It is displayed using differentiating hues on the border. The time length is set with the size variable and is proportional to the thickness of the border. Main forest stands are written in labels in order to not overload symbols, especially when background layer is set to remain visible within the polygons. The proposed map displayed as follows synthetizes and gives a spatial overview of a part of the great amount of information concerning places of interest. What can be assumed by interpreting the map is that the red deer tends to have intense research effort behaviour mainly during day in young plantations and cuttings, and one such behaviour is observed at night in an open field.

Figure 3 presents an alternative map to the map in Figure 2. The focus is time and land cover information. Specifications are: use of circle geometry, display of the same four attributes than in Figure 2, no constraint on the visibility of background layers within places of interest. Added lines between GPS points were symbolized in 
white colour in order to add an overview about the movement extent and shape.

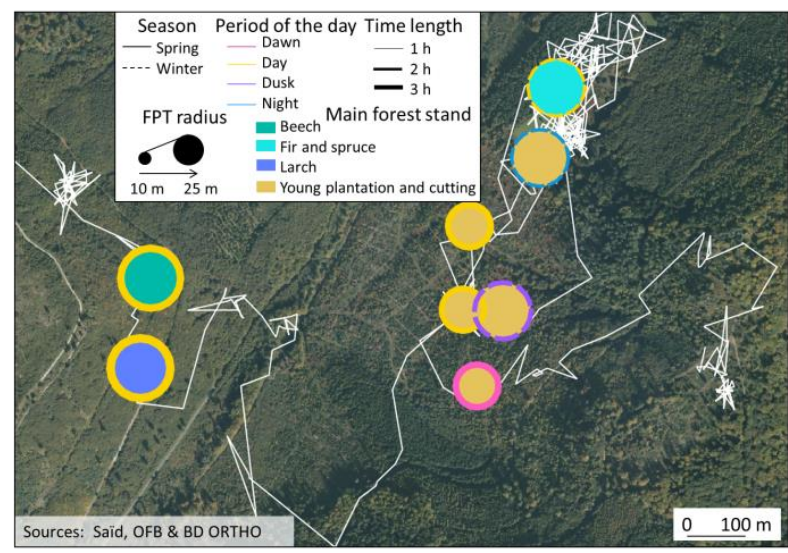

Figure 3. Foraging places of interest of a red deer during three days: circle geometries were displayed with a radius value in meters equal to the lowest radius value selected with FPT.

Attributes in Figure 3 were associated with the same visual variables than in Figure 2. Due to the release of constraint about visibility of the background, the attribute about the main forest stand is displayed using filled colours in the circle symbol. Colours correspond to standards in French national forest maps. The circle geometry allows using the radius length and visualizing the FPT first radius which is the smallest significant value and a direct result from the movement analysis.

\subsubsection{Displaying functional space}

Distinct maps of functional space were produced for roe deer and for red deer, even if preference and avoidance appeared as relatively close at the spatial scale of the study site. Figure 4 shows a map of patches qualified with the defined gradient of potential interest for red deer species. The shade visual variable is exploited to outline this gradient.



Figure 4. Estimated functional space for red deer, qualified with a gradient of potential interest. Patches were defined based on favorable or avoided forest stands and other landscape elements.

On the proposed map, the geometries of roads, paths, buildings and waterways in existing geographical databases were added. Their display enhances landscape overview by indicating detailed landscape features and so increasing contextual knowledge. Roads and paths are meaningful, though ambivalent, features as they may be associated both to disturbance for fauna and to interesting open areas facilitating movements and containing vegetation species. They are also relevant to map for foresters' reachability within the study site, aside with buildings like service warehouses. Waterways may be associated with animal presence due to specific vegetation. Hydrography is globally related to topography like valley bottoms and potentially to surrounding steep slopes.

\section{Discussion}

The final outcomes of the work are maps providing a meaningful reading of a forested site for roe deer and red deer by displaying characterized places of interest. Several stages were necessary to propose such maps: characterizing relevant pieces of information needed to understand fauna and their interactions with landscape elements, and displaying maps.

Concerning the stage about characterizing animal space use, our approach was to select a dataset with individual GPS locations and available geographical databases. Movement patterns were modelled, especially foraging stops using the FPT method and corresponding to ARS places of interest which are important in a forestry context. They can be further enriched with other modelled behaviours such as rest, travel of different types (exploratory, migratory) and also social interactions. Spatial and statistical analyses were carried out in order to locate and extract significant observed space use: spatial preferences and avoidance based on MannWhitney and Chi-square tests. Results could be confirmed and weighted using a statistical model like in Cobben et al. (2009). Geographical databases could be completed with information remotely extracted from satellite or aerial images or collected on the field, targeting specific landscape features: spatial density in forest stands, number of different plant species, heights of vegetation, small forest clearings, meadows and crop fields, road and path surfaces, type of use for buildings. The functional space corresponding to potential patches in favour or not for an animal species corresponds to an interesting complement to located observed places of interest, even if information is estimated and geometries and attributes of patches simplified (forest stands, slopes). Characterizing one individual places of interest is not significant for a whole species, though it contributes and may add nuance in general knowledge about this species. The personality of the animal and the context of the study site may balance shared spatial behaviours and their temporality. For instance, even if red deer is known to be more active at dawn and dusk and to be present in open fields, foraging behaviour can be observed in the middle of the day under forested cover. In our case, taking into account two different animal species allowed considering different extents and characterizations of space use. Red deer moves on greater distances and covers larger home ranges that roe deer. They are likely to exploit and cross more forest patches, thus more landscape features are likely to be relevant to analyse and then to visualize. This statement also suggests that the levels of detail of mobilized geographical databases might be more suitable for analysing red deer's space use than roe deer's. 
The stage about designing maps aimed at offering a synthetic overview of observed and then assumed places of interest from analysis results. Different displays were proposed to fit in a geographical portal. They respond to constraints for consistency of the overall symbolisation, and target an end-use in forest management. Background layers are one parameter to set: images can be more difficult to interpret than base maps, though more realistic. Symbolisation was defined based on the properties of visual variables, which were applied according to the attribute values of the ARS geometries. Map in Figure 2 is synthetic and focuses on ARS behaviour. It allows a fast reading. Map in Figure 3 displays the extent of the whole movements and the FPT first radius. It is more adapted for an end-user interested in the detailed animal spatial behaviour besides the ARS behaviour. Some parts of the map are however crowded, e.g. in the forest clear cut. Design could change depending on zoom in and out (Vrotsou et al., 2015), e.g. for displaying ARS geometries and movement lines. It could also be improved regarding conflicts between values of visual variables, e.g. similar conventional colours for main forest stands and periods of the day in Figure 3.When maps include several animals and animals' species, here roe and red deer, information about individuals and species are displayed using visual variables. Opportunities to display time and spatial information useful to forestry are thus reduced. Test labels remain an option like in Figure 2 about main forest stands even if efforts are on symbolisation based on graphic semiotics. Label display could be dynamic or responsive to an interface-user's action, allowing access to more written information. Map proposals for the functional space gave a spatially exhaustive cover of the study site, qualified according to potential interest. Such visualisation can help highlighting spatial connection between patches of high interest and considering natural habitat fragmentation.

Next step of the work is to evaluate the current maps. Evaluation concerns their graphical legibility and the effective interest for a forestry end-use. Surveys are planned to be carried out (Nivala et al., 2008; Brewer et al., 2003). The following step would be to include in the maps more relevant information, besides places of interest. Movement dynamics could be symbolized in movement lines based on estimated speeds between GPS points. Spatial distribution of animal locations within landscape elements could be explicitly displayed or schematized: distances to the edge of the forest, to clearings, to roads or paths. Observed places of interest are mainly within forest stands, though the use of forest edges and open field environments for mainly forested animals like roe and red deer could be outlined (Gottardi, 2011). Detailing and visualising landscape configurations could be relevant as correlations and interactions between features exist.

\section{Conclusion}

In this article, places of interest for fauna corresponding to foraging behaviour were analysed based on collected movement data and landscape descriptions. Foraging places are likely to be prioritized during forest management processes as some of them can be sensitive to pressure. The focus was about roe deer and red deer and the study site is mainly covered by forest, hilly and sparsely inhabited. Maps were produced so that to display information meaningful about animal space use and readable for forestry end-use. The interesting add-on is to be able to cross-reference analysis results about fauna and spatiotemporal environment and then to visualize them on a single geographical portal. Mapping located places of interest and related relevant information relies on cartographical rules and combinations of visual variables. The challenge was to communicate on one type of objects, in our case ARS point clusters or polygons obtained with the FPT method, carrying much time, spatial and individual information while proposing a legible map. An important remaining perspective would be to indicate on maps indexes about reliability and representativeness of the displayed information. Maps could then be read and used with some explicit critical complements.

\section{References}

Andrienko, G., Andrienko, N., Olteanu-Raimond, A.-M., Symanzik, J. and Ziemlicki, C. (2012). Towards Extracting Semantics from Movement Data by Visual Analytics Approaches. Proceedings of GIScience workshop GeoVisual Analytics, Time to Focus on Time, 18 September 2012, Columbus, USA.

Ager, A.A., Johnson, B.K., Kern, J.W. and Kie, J.G. (2003). Daily and seasonal movements and habitats use by female rocky mountain elk and mule deer. Journal of Mammalogy. Volume 84 (3), p. 1076-1088.

Badard, T., Braun 2004). A.: OXYGENE : une plateforme ouverte pour le déploiement de services web géographiques. Le Monde des Cartes, Comité Français de Cartographie. Volume 181, p. 32-41.

Bertin, J. (1967). Sémiologie Graphique. GauthierVillars/Mouton Eds., Paris.

Boulanger, V., Baltzinger, C., Saïd, S., Ballon, P., Picard, J.-F. and Dupouey, J.-L. (2015). Decreasing Deer Browsing Pressure Influenced Understory Vegetation Dynamics over 30 Years. Annals of Forest Science, Volume 72, p. 367-378.

Brewer, C., Hatchard, G., and Harrower, M. (2003). ColorBrewer in print: a catalog of color schemes for maps. Cartography and Geographic Information Science. Volume 30 (1), p. 5-32

Buard, E. (2011). Pratiques spatiales des populations animales : analyses par les trajectoires. Proceedings of 10th Théo Quant, Besançon, France, p. 10-14

Buschmann, S., Trapp, M. and Döllner, J. (2014). RealTime Animated Visualization of Massive Air-Traffic 
Trajectories. Proceedings of the International Conference on Cyberworlds in Cantabria, Spain, p. 174181.

Cobben, M.M.P., Linnell, J.D.C., Solberg, E.J., and Andersen, R. (2009). Who wants to live forever? Roe deer survival in a favourable environment. Ecological Research. Volume 24, p. 1197-1205.

Ethier, K. and Fahrig, L. (2011). Positive effects of forest fragmentation, independent of forest amount, on bat abundance in eastern Ontario, Canada. Landscape Ecology, Volume 26, p. 865-876.

Etienne, L., Devogele, T. and Bouju, A. (2010). SpatioTemporal Trajectory Analysis of Mobile Objects Following the Same Itinerary. Proceedings of the International Symposium on Spatial Data Handling (SDH) Hong Kong.

Fauchald, P. and Tveraa, T. (2003). Using First-Passage Time in Analysis of Area-Restricted Search and Habitat Selection. Ecology. Volume 84 (2). p. 282-288.

Forman, R. T. T., Godron, M. (1986) Landscape Ecology. Eds. John Wiley \& Sons, 619 p.

Gottardi, E. (2011). Landscape openness effect roe deer, Capreolus capreolus, behavior. $\mathrm{PhD}$ thesis, University Paul Sabatier, Toulouse.

Hanley, T. (1996). Potential role of roe deer (Cervidae) as ecological indicators of forest management. Forest Ecology and Management, Volume 88, p. 199-204.

Kjellander, P., Gaillard J.-M., Hewison, A.J.M. (2006). Density-dependent responses of fawn cohort body mass in two contrasting roe deer populations. Oecologia, Volume 146 (4), p. 521-530

Le Corre, M., Pellerin, M., Pinaud, D., Van Laere, G., Fritz, H. and Saïd, S. (2008). A multi-patch use of the habitat: testing the First-Passage Time analysis on roe deer paths. Wildlife Biology.

Matthiopoulos, J. (2003). The use of space by animals as a function of accessibility and preference. Ecological Modelling. Volume 159 (2-3), p. 239-268.

Mysterud, A. (1999). Seasonal migration pattern and home range of roe deer (Capreolus capreolus) in an altitudinal gradient in southern Norway. Journal of Zoology. Volume 247, p. 479-486.

Náhlik, A., Sándor, G., Tari, T. and Király, G. (2009). Space use and activity patterns of red deer in a highly forested and in a patchy forest-agricultural habitat. Acta Silvatica \& Lignaria Hungarica. Volume 5, p. 109-118.

Nellemann, C., Vistnes, I., Jordhoy, P. and Strand, O. (2001). Winter distribution of wild reindeer in relation to power lines, roads and resorts. Biological Conservation, Volume 101, p. 351-360.

Nivala, A.M., Brewster, S. and Sarjakoski, L.T. (2008). Usability Evaluation of web Mapping Sites. The Cartographic Journal. Volume 45 (2), p. 129-138.

Olsoy, P. J., Forbey, J.S., Rachlow, J. L., Nobler, J. D., Glenn, N. F., and Shipley, L. A. (2015). Fearscapes:
Mapping functional properties of cover for prey with terrestrial LiDAR. BioScience, Volume 65, p. 74-80.

Plumptre, A. J. (1993). The effects of trampling damage by herbivores on the vegetation of the Parc National des Volcans, Rwanda. African Journal of Ecology, Volume 32 (2), p. 115-129.

Rooney, T. P. (2001). Deer impacts on forest ecosystems: a North American perspective. Forestry, Volume 74 (3), p. 201-208.

Saïd, S., Gaillard, J.-M., Duncan, P., Guillon, N., Guillon, N., Servanty, S., Pellerin, M., Lefeuvre, K., Martin, C. and Van Laere, G. (2005). Ecological correlates of home-range size in spring-summer for female roe deer (Capreolus capreolus) in a deciduous woodland. Journal Zoology, The Zoological Society of London. Volume 267, p. 301-308.

Spaccapietra S., Parent C., Damiani M. L., de Macedo J. A., Porto F. and Vangenot C. (2008). A conceptual view on trajectories. Data Knowledge Engineering, Volume 65 (1), p. 126-146.

Spretke, D., Janetzko, H. and Mansmann, F. (2011). Exploration through Enrichment: A Visual Analytics Approach for Animal Movement. Proceedings of the $19^{\text {th }}$ ACM SIGSPATIAL, Chicago and New-York, USA, p. 421-424.

Storms, D., Saïd, S., Hamann, J.-L. and Klein, F. (2004). Détermination intra-interspécifiques de la sélection de l'habitat par le cerf et le chevreuil en milieu forestier. ONCFS Scientific Report, p. 56-59.

Storms, D., Aubry, P., Hamann, J.-L., Saïd, S., Fritz, H., Saint-Andrieux, C. and Klein, F. (2008). Seasonal variation in diet composition and similarity of sympatric red deer Cervys elaphus and roe deer Capreolus capreolus. Wildlife Biology. Volume 14 (2), p. 237-250.

Vrotsou, K., Janetsko; H., Navarra, C., Fuchs, G., Spretke, D., Mansma, F., Andrienko, N. and Andrienko, G. (2015). SimpliFly: A Methodology for Simplification and Thematic Enhancement of Trajectories. IEEE Transactions on Visualization \& Computer Graphics. Volume 21, p. 107-121.

Widmer, O., Saïd, S., Miroir, J., Duncan, P., Gaillard, J.M., Klein F. (2004). The effects of hurricane Lothar on habitat use of roe deer. Forest Ecology and Management, Volume 195, p. 237-242. 